Jurnal Keperawatan Padjadjaran

ISSN 2338-5324 (print)

ISSN 2442-7276 (online)

Online di http://jkp.fkep.unpad.ac.id

DOI : $10.24198 / \mathrm{jkp}$

\title{
Comparison of Central Venous Pressure (Cvp) Score Among Patients on Mechanical Ventilator With Head of Bed (Hob) Elevation 30O; Neutral, Right, and Left Side Positions
}

\author{
Setiyawan ${ }^{1}$, Kusman Ibrahim $^{2}$, Titin Mulyati ${ }^{3}$ \\ ${ }^{1}$ STIKes Kusuma Husada Surakarta, Surakarta, Indonesia \\ ${ }^{2}$ Faculty of Nursing Universitas Padjadjaran, Bandung, Indonesia \\ ${ }^{3}$ General Intensive Care Unit RSUP dr. Hasan Sadikin, Bandung, Indonesia \\ Corresponding Email: etya1025@gmail.com
}

Submitted: 11-04-2018 Accepted: 08-02-2019 Published: 11-04-2019

\begin{abstract}
Early mobilization is important for critical patients to improve cough reflex, relieve bronchial secretions, facilitate the work of mucociliary drainage muscles, and to prevent ventilator-associated pneumonia and pressure sores. However, at the same time patients often experience changes in vital signs due to fluctuating conditions. Central Venous Pressure (CVP) measurement is often necessary to monitor the central circulatory system. Unfortunately, in a clinical setting, the patient's position must be changed first to a 30o neutral head of bed (HoB) position rather than the left or right side HoB position. This study aims to determine differences in CVP scores among patients in mechanical ventilation at $30 \mathrm{o} H \mathrm{HoB}$ position elevation in a neutral, right, and left. This quantitative comparative study involved 24 subjects who were recruited sequentially. Data were analyzed using ANOVA. The results showed that the mean CVP value at the elevation of the neutral HoB position elevation was 13.5 \pm 3.96 , the HoB elevation on the right side was $12.8 \pm 4.16$, and the HoB elevation on the left side was $14.4 \pm 4.17$. There is a significant difference $(\mathrm{p}<0.05)$ among the three positions. The post hoc analysis test found that the HoB 300 neutral position vs the left side position was higher and significantly different from the HoB 30o elevation in the neutral vs right side position $(p<0.05)$. This study suggests that nurses need to consider changes in CVP values while changing the position of the patients with a HoB elevation of 30o in a neutral position, right side, and left side. Although statistically there is a difference among the three positions, in fact the difference in value is less than $1 \mathrm{cmH} 2 \mathrm{O}$ which is not clinically evident.
\end{abstract}

Keywords: Central venous pressure, HoB elevation, Mechanical ventilation 
Setiyawan: Comparison of Central Venous Pressure (CPV) Score among Patients on Mechanical Ventilator

\section{Introduction}

Intensive care is one of the nursing services for patients with acute or chronic illnesses in emergency situations, critical who require monitoring of vital functions, more specifically intensive therapy and immediate action that cannot be given in the general care room (Linda, Kathleen \& Mary, 2010). Hemodynamic disorders are one reason patients need intensive care unit (ICU). One of the hemodynamic assessments that are often carried out in the ICU is the measurement of right atrial pressure or central venous pressure/ CVP.

Right atrial pressure data helps support the diagnosis, knows the patient's condition and provides appropriate therapy. The current CVP is an indicator that is still reliable in terms of estimating the intravascular volume adequacy (Izzakovic, 2008). The CVP measurement results in interpreting the pressure of the right atrium which shows blood volume status, heart effectiveness as a pump, and vascular tone which indirectly describes the initial right heart load or right ventricular pressure at the end of the diastole from the venous return. CVP measurement is carried out if the patient has hypotension that does not respond to basic clinical management, ongoing hypovolemia and / or the patient needs an inotropic infusion that can be measured at any time or incidentally (Cole, 2007; Scales \& Fernandes, 2010). Normal CVP values using a manometer system are 5-10 cmH2O (Cole, 2007).

The recommended position for CVP measurement is the position of head of bed (HoB) elevation $30 \mathrm{o}$. At the HoB elevation 30 o position, the blood flow pressure gradient from the inferior vena cava leading to the right atrium is able to deal with vascular resistance and right atrial pressure, thereby increasing venous return and increasing right ventricular filling (preload), leading to increased stroke volume and cardiac output. The gravitational force of the patient's position significantly affects venous return, cardiac output, and venous pressure (Kim \& Sohng, 2006). However, changes in right or left side position in critical patients with mechanical ventilation are important as early mobilization to prevent secondary complications such as nosocomial pneumonia infections, thombophlebitis, muscle atrophy, accumulation of respiratory tract secretions, reducing pain on the paralyzed side, facilitating circulation blood, contractures, joint stiffness and pressure sores (Yemima, 2007)

Positioning side to side can prevent pressure sores is also very effective in increasing the process of removing bronchial secretions on the basis of gravitational effects. This stimulates the secretion to move from one or more lung segments to the airway where the secretions can come out by mouth by coughing reflex or by mechanical aspiration and can increase the strength of the diaphragmatic breathing muscles so that breathing can be adequate and the process of weaning off the ventilator can be faster and the risk of pneumonia can be minimized (Kathleen, 2010).

However, changes in position can cause some negative potential effect for critical patients. When the patient is in the right side position, the return of blood from the inferior part through the inferior vena cava (IVC) experiences kinking because the close IVC to the right facilitates suppression by the kidney, and anatomically located the heart in the left hemithorax, when tilted to the right, the left side of the heart slightly pushes to the right which causes a decrease in the diameter of the right atrial space, so that the blood volume / venous return decreases resulting in a greater decrease in blood pressure compared to the lateral left position (Hazebroek \& Bonjer, 2011) This has the potential to affect the value of the CVP.

Apart from the above, the change in position is not too much a concern for nurses in treating CVC-installed patients and mechanical ventilation to evaluate the difference in CVP values. Observations of researchers during intensive clinical learning, all critically ill patients with hemodynamics were stable either installed with mechanical ventilation and CVC or not, in their care they were transferred to the position every 2 hours as a form of early mobilization. During the transfer of position, patients often experience changes or decrease in vital signs because of their fluctuating conditions and immediate monitoring of CVP values to monitor intravascular volume adequacy, so 


\section{Setiyawan: Comparison of Central Venous Pressure (CPV) Score among Patients on Mechanical Ventilator}

that the fluid challenge test in determining the appropriate action is aggressive and rapid resuscitation or requires additional drugs. However, so far the patient's position to obtain a CVP value must be changed first in a neutral $\mathrm{HoB}$ elevation position $30 \mathrm{o}$. This allows that the measurement of CVP values must be immediately carried out by health workers, especially nurses at that time without having to change their position first so that the CVP value can be known and analyzed to determine the action or therapy more quickly and precisely so that the impact of changes and vital signs and deterioration of the patient's condition can be minimized and even prevented.

Quick, short and sudden changes in position can increase oxygen consumption, cause changes in the hemodynamic status of patients who are unstable and time-consuming and health workers in treating critical patients, especially patients with myocardial infarction who are given supination, pronation, right lateral, and left lateral positions (Siepe, et. al. 2005). According to Kozier \& Erb, (2009), a change in position that is too fast causes a decrease in venous return, a decrease in the mean arterial pressure (MAP) and central venous pressure which results in a decrease in cardiac output. The purpose of this study was to examine the differences of CVP scores among patients with $\mathrm{HoB}$ elevation $30 \mathrm{o}$ in a neutral, right side, and left side position.

Table 1 Characteristics of the Subjects $(n=24)$

\begin{tabular}{llcc}
\hline & Characteristics & Frequency (f) & Percentage (\%) \\
\hline Age (years) & $18-40$ & 10 & 41.7 \\
& $41-60$ & 11 & 45.8 \\
\multirow{3}{*}{ Gender } & $>60$ & 3 & 12.5 \\
\multirow{3}{*}{ Disease group } & Male & 13 & 54.2 \\
& Female & 11 & 45.8 \\
& Internal disease & 3 & 12.5 \\
& Digestive Surgery & 5 & 20.8 \\
& Neurosurgery & 3 & 12.5 \\
& Neurology & 5 & 20.8 \\
& Obstetrics & 5 & 20.8 \\
& Cardiology & 2 & 8.3 \\
& Surgical Oncology & 1 & 4.2 \\
\hline
\end{tabular}

\section{Method}

This is a quantitative comparative study. The population of the study was all patients admitted in the General Intensive Care Unit (GICU) in a teaching hospital of West Java Province. Twenty-four patients were recruited consecutively with the inclusion criteria; having stable hemodynamic conditions and their aged between 18 to 65 years. Ethical approval was obtained from the Health Research Ethic Committee Faculty of Medicine Universitas Padjadjaran with the number 194/UN6.C1.3.2/KEPK/ values, then validated by a senior nurse who incharge in the shift time as data taken. CVP measurements were started at the neutral $\mathrm{HoB}$ elevation $30 \mathrm{o}$ position for ten minutes, then continued at the right and left side positions. CVP was measured using a manometer and recorded on the measurement sheet. Data were checked for normally by using Shapiro Wilk test. Data were normally distributed $(\mathrm{p}=$ $0.785)$. Anova test was performed to examine the differences among three data means.

\section{Result}

The characteristics of the subjects included age, gender, and disease group were presented in the table 1 below. $\mathrm{PN} / 2015$. The researcher measured the CVP 
Based on the mechanical ventilation mode used, almost half of the subjects used either CPAP or SIMV mode. More than half of the subjects used PEEP of $5 \mathrm{CmH} 2 \mathrm{O}$. All subjects' heart rate within a normal range of 60-100 times / minute. Half of the subjects had MAP between 70-90 $\mathrm{mmHg}$ as presented in the table 2.
The subjects' CVP value measured in the position of a neutral $\mathrm{HoB}$ elevation $30 \mathrm{o}$, right side, and left side HoB 30o positions. Most of the subjects showed their CVP values $>10$ $\mathrm{CmH} 2 \mathrm{O}$ in all three positions (Table 3 ).

Mean score of CVP values at $\mathrm{HoB}$ elevation 30o left side position was consider a the highest (14.4 \pm 4.17$)$ compare to the HoB

Table 2 Mode of Mechanical Ventilation, PEEP, and Hemodynamic Status of the Subjects $(n=24)$

\begin{tabular}{lccc}
\hline \multicolumn{1}{c}{ Use of Mechanical Ventilation } & Frequency & $(\mathbf{\%})$ \\
\hline Mode Ventilator & VC & 1 & 4.2 \\
& SIMV & 10 & 41.7 \\
& CPAP & 11 & 45.8 \\
\multirow{4}{*}{ PEEP (cmH2O) } & PS & 2 & 8.3 \\
& 5 & 15 & 62.5 \\
\multirow{3}{*}{ Hemodynamic Status } & $6-10$ & 9 & 37.5 \\
Heart Rate & $11-15$ & 0 & 0 \\
& & & \\
\multirow{4}{*}{ Sistolik } & $<60$ & 0 & 0 \\
& $60-100$ & 24 & 100 \\
& $>100$ & 0 & 0 \\
Diastolik & $<100$ & 0 & 0 \\
& $100-140$ & 21 & 87.5 \\
& $>140$ & 3 & 12.5 \\
MAP & $<70$ & 11 & 45.8 \\
& $70-90$ & 13 & 54.2 \\
& $90-110$ & 0 & 0 \\
& $<70$ & 2 & 8.3 \\
& $70-90$ & 13 & 54.2 \\
& $>90$ & 9 & 37.5 \\
\hline
\end{tabular}

Table 3 CVP Values at 30o Head of Bed (HoB) Elevation Neutral, Right Side, and Left Side Positions (n=24)

\begin{tabular}{|c|c|c|c|c|c|c|c|}
\hline \multirow[t]{3}{*}{ Measurement Position } & \multicolumn{6}{|c|}{ CVP Value (CmH2O) } & \multirow{3}{*}{$\begin{array}{c}\sum \\
\mathbf{f} \\
\% \\
\end{array}$} \\
\hline & \multicolumn{2}{|c|}{$<5$} & \multicolumn{2}{|c|}{$5-10$} & \multicolumn{2}{|c|}{$>10$} & \\
\hline & f & $\%$ & f & $\%$ & f & $\%$ & \\
\hline HoB elevation $30^{\circ}$ neutral & 0 & 0 & 6 & 25 & 18 & 75 & $24(100)$ \\
\hline $\begin{array}{l}\text { HoB elevation } 30^{\circ} \text { right side } \\
\text { position }\end{array}$ & 0 & 0 & 9 & 37.5 & 15 & 62.5 & $24(100)$ \\
\hline $\begin{array}{l}\text { HoB elevation } 30^{\circ} \text { left side } \\
\text { position }\end{array}$ & 0 & 0 & 3 & 12.5 & 21 & 87.5 & $24(100)$ \\
\hline
\end{tabular}


Setiyawan: Comparison of Central Venous Pressure (CPV) Score among Patients on Mechanical Ventilator

Table 4 Mean Score of CVP Values among Head of Bed (HoB) Elevation $30^{\circ}$ Neutral Right, and Left Side Positions

\begin{tabular}{ccc}
\hline Measurement Position & Mean \pm SD $(\mathbf{C m H 2 O})$ & p \\
\hline HoB elevation $30^{\circ}$ neutral & $13.5 \pm 3.96$ & 0.000 \\
HoB elevation $30^{\circ}$ right side & $12.8 \pm 4.16$ & \\
HoB elevation $30^{\circ}$ left side & $14.4 \pm 4.17$ & \\
\hline
\end{tabular}

Table 5 Post Hoc Paired Wise Comparations CVP Value between Head of Bed (HoB) Elevation $30^{\circ}$ Neutral vs Right Positions and Neutral vs Left Side Positions

\begin{tabular}{ccc}
\hline Measurement Position & CVP Value \\
\cline { 2 - 3 } & $\begin{array}{c}\text { Mean difference (cmH2O); } \\
\text { IK 95\% }\end{array}$ & $\mathbf{p}$ \\
\hline HoB elevation 30 : Neutral vs Right Side & $0.69(0.248-1.127)$ & 0.004 \\
HoB elevation 30 $:$ Neutral vs Left Side & $0.85(0.374-1.334)$ & \\
\hline
\end{tabular}

elevation 30o neutral and right side positions. ANOVA test showed there was signifficant diffecrence among means score of $\mathrm{HoB}$ elevation $30 \mathrm{o}$ neutral, right side, and left side position $(\mathrm{p}<0.05)$ (Table 4$)$. A post hoc analysis of Paired Wise Comparations was carried out to compare two mean difference, and the results showed there was signifficant difference between CVP values at positions of $\mathrm{HoB}$ elevation $30 \mathrm{o}$ (neutral vs right side) and $\mathrm{HoB}$ elevation $30 \mathrm{o}$ (neutral vs left side) $(\mathrm{p}<0.05)$ (Table 5)

\section{Discussion}

The condition of critical patients in intensive care requires strict and accurate hemodynamic monitoring, such as the rise and fall of blood pressure that can change at any time which greatly affects or causes the shutdown of the functions of other body organs, and even patients who are treated intensively in a short time can be experiencing multiorgan dysfunction syndrome (MODS). The most common cause of MODS is a decrease in perfusion (Marik \& Cavallazzi, 2013). Decreased perfusion is caused by a decrease in hemodynamics, one of which can be caused by a decrease in CVP values (Mulyati, Fatimah \& Susilaningsih, 2012). CVP values can be decreased, one of which is caused by a hypovolemic fluid status disorder.

In table 3, it can be seen that the CVP value of the $\mathrm{HoB}$ elevation $30^{\circ}$ position is neutral or before a change in position is mostly above the value of $10 \mathrm{cmH} 2 \mathrm{O}$. The value of CVP in critically ill patients tends to increase, this is one form of therapy in meeting the fluid needs of critical patients with the aim of maintaining intravascular fluid in preventing the occurrence of hypovolemia, shock and tissue hypoperfusion and worsening tissue damage (Marik \& Cavallazzi, 2013). Patients with certain conditions to meet and maintain positive airway pressure need high PEEP and in this study, there were 9 respondents with the use of a 6-10 $\mathrm{mmHg}$ PEEP setting. CVP values measured in the HoB elevation $30^{\circ}$ neutral position tend to increase can also be caused by the use of PEEP between 6-10 $\mathrm{mmHg}$, because an increase in PEEP significantly increases CVP values (Cao, Liu \& Chen, 2008; Mulyati, Fatimah \& Susilaningsih, 2012). Furthermore, Mulyati, et al., (2012) found that the mean difference in CVP value of PEEP $5 \mathrm{cmH} 2 \mathrm{O}$ to $10 \mathrm{cmH} 2 \mathrm{O}$ PEEP was $2 \mathrm{mmHg}$.

Theoretically, at the HoB elevation position $30^{\circ}$ the return flow of blood from the inferior part to the right atrium is very good. This is because vascular resistance and right atrial pressure are not too high, so venous return to the right atrium is quite good and right ventricular filling pressure (preload) increases, which ultimately increases stroke volume and cardiac output (Kim \& Sohng, 2006) Changes in the position of neutral $\mathrm{HoB}$ elevation $30 \mathrm{o}$ laterally or tilted affect the backflow of blood leading to the heart. Cicolini et al. (2010) stated that the head up or HoB position had an effect on changes in blood pressure and central venous pressure. Different positions affect hemodynamics 
including the venous system.

Changing the angled position to the right can result in changes in the shape of the chest, abdomen and decreased intrathoracic pressure which can reduce venous return, cardiac output, and MAP. In this study there was a decrease in CVP value when the HoB elevation $30 \mathrm{o}$ position was tilted right. In the study of Lan et al. (2010) and Thomas et al. (2007), the hemodynamic effect is more common in the lateral position than the supine position as a result of decreased venous return because the inferior vena cava is bent. The position of the inferior vena cava adjacent to the right side facilitates suppression by the kidneys. Decreasing almost $10 \%$ of the volume at the end of the right ventricular diastolic at right lateral position, the condition is associated with a decrease in the amount of blood volume leading to the atrium even though the cardiac index tends not to change.

According to Lorenzo et al. (2012), the size of the inferior vena cava (IVC) is closely related to the results of the CVP assessment. The study states that measuring IVC diameter through ultrasonography can be used as determination of CVP values in indicating fluid volume status (Citilcioglu, 2014; Wiwatworapan, Ratanajaratroj \& Sookananchai, 2012). In the right side $\mathrm{HoB}$ 30o position, IVC has kinking because the close IVC to the right facilitates suppression by the kidneys, and anatomically the location of the heart in the left hemithorax, when tilted to the right, the left side of the heart pushes to the right which causes the diameter of the right atrial space decreased, so that the volume of blood / venous return has decreased so that the impact on the decrease in blood pressure is greater when compared with the left lateral position (Hazebroek \& Bonjer, 2011). The results of a study conducted by Yoon et al (2006) that the CVP value at right-angled position shows a lower result than the head up or supine position and it is recommended that the level of the transducer should be placed higher. According to Daihua et al., (2012) there is significant influence between changes in position on stroke volume in septic patients with mechanical ventilation. Furthermore, it was stated that head up 30o increases stroke volume and MAP, at right side $\mathrm{HoB} 30$ o position, MAP results are $81 \pm$
12.3 while HoB 30 o is left side $83.8 \pm 11.6$. Stroke volume is often used to predict fluid responsiveness based on the results of CVP assessment, so that in this case stroke volume is indirectly the result of a CVP value (Marik \& Cavallazzi, 2013).

Based on this explanation, the results of this study corroborate the statement of research that has been carried out by Daihua et al., (2012) and Marik \& Cavallazzi, (2013). right side due to an increase in the diastolic end diameter of the right ventricle and the right atrium in the left position, allowing the high return to the right atrium (Sen, Aydin \& Discigil, 2007; Aries et al., 2011). Evaluation of inferior vena cava from echocardiography in subcostal display showed that the IVC diameter decreased which was observed at the end of inspiration when intrathoracic pressure was negative and caused an increase in the ventricular right (RV) in filling from systemic veins. IVC size was significantly affected by the position of the patient, the smallest in the right lateral position, the middle in the supine position, and the largest in the left lateral position which correlated with the right atrial pressure (Ginghina et al. 2009).

Referring to a study conducted by Maas, Grerts \& Jansen (2011), this study found the same finding trend. Gravitational changes due to changes in position affect numerous cardiovascular (CV) and neurohumoral adjustments of gradient friction calculations on MAP and CVP values, where changes in position towards the left lateral increase in the diameter of the inferior vena cava which results in increased right atrial pressure of 1 $\mathrm{mmHg}$ and finally increase CVP. Changes in the left side position have an impact on increasing preload as a result of accumulated blood volume $(300-800 \mathrm{ml})$ in the upper arm and backflow from the lower vein which is then detected by atrial baroreceptors activity and stimulates the sympathetic system and heart rate and contractility which can increase preload and cardiac output which correlates with right atrial pressure. This mechanism ends with an increase in CVP. However, this does not benefit patients with heart failure or after infarction without bradycardia because the heart has decreased function (Maas, Grerts \& Jansen, 2011). 
Setiyawan: Comparison of Central Venous Pressure (CPV) Score among Patients on Mechanical Ventilator

Based on statistical value using anova test and the post-hoc paired wise comparations test, there were significant differences in CVP values in patients with mechanical ventilation between the position of HoB elevation 30o in a neutral position, right side and left side. The average CVP difference is 0.69 and 0.85 $\mathrm{cmH} 2 \mathrm{O}$ (less than $1 \mathrm{cmH} 2 \mathrm{O}$ ). In clinical judgment, these differences do not show significant differences, because it will not lead to differences in clinical interpretations and therefore these differences will not affect the determination of diagnosis and selection of therapy, noting that the respondents in this study were $25 \%$ in normal CVP values, but if the patient is at a low or high CVP value, it could be a clinical consideration in determining the intervention (Mulyati, Fatimah \& Susilaningsih, 2012). Another implication of the results of this study, CVP can be measured in the position of the right side or left side $\mathrm{HoB}$ elevation $30 \mathrm{o}$ without having to change the position of the HoB elevation $30 \mathrm{o}$ to a neutral position.

\section{Conclusion}

Based on the results of the study it can be concluded that there was a significant difference in CVP values of patients with mechanical ventilation among HoB elevation $30 \mathrm{o}$ neutral, right side, and left side positions. Mean score of $\mathrm{HoB}$ elevation $30 \mathrm{o}$ left side position was the highest. The mean difference between HoB elevation $30 \mathrm{o}$ neutral and left side position was higher than neutral and right side position. There was significant difference between mean score difference of $\mathrm{HoB}$ elevation 30o neutral-left side and neutral-right side postions. Although it was statistically difference, in fact, the values less than $1 \mathrm{CmH} 2 \mathrm{O}$ which perhaps clinically did not have significant meaning.

\section{References}

Aries, M.J.H., Aslan, A., Elting, J.W.J., Stewart, R.E., Zijlstra, J.G., Keyser, J.D., and Patrick, V.A.J. (2011). Intra-Arterial Blood Pressure Reading In Intensive Care Unit Patients In The Lateral Position. Journal of
Clinical Nursing, 21, 1825-1830.

Cao, F., Liu, T.F., Chen, R.L. (2008). Effect of Positve End Ex $\neg$ piratory Pressure on Central Venous Pressure and Common Iliac Venous Pressure in Mechanically Ventilated Patient. Zhonggou Wei Zhong Bing Jijiu Yi Xue, 20, 341-4.

Cicolini, G., Gagliardi, G., \& Ballone, E. (2010). Effect of Fowler's Body Position on Blood Pressure Measurement. Journal of Clinical Nursing, 19, 23-24.

Citilcioglu, S., Sebe, A., Ay, M.O., Icme, F., Avci, A., Gulen, M., Sahan, M., Satar, S. (2014). The Relationship Between Inferior Vena Cava Diameter Measured by Bedside Ultrasonography and Central Venous Pressure Value. Pak Journal Medical Science. 30(2):310-315.

Cole, E. (2007). Measuring Central Venous Pressure. Nursing Standard, 22(7).

Daihua, Y., Chai Wei, C., Xude, S., Linong, Y., Changjun G., Hui Z. (2012). The Effect of Body Position Changes on Stroke Volume Variation In 66 Mechanically Ventilated Patients With Sepsis. Journal of Critical Care, 27, 416.e7-416.e12.

Gelman, S., (2008). Venous Function and Central Venous Pressure. Anesthesiology. 108:735-48.

Ginghina, C., Beladan, C.C., Iancu, M., Calin, A., Popescu, B.A. (2009). Respiratory Maneuvers In Echocardiography: a Review of Clinical Applications. Cardiovascular Ultrasound, 7(42) doi:10.1186/1476-7120-742.

Hazebroek, E.J., Bonjer, H.J. (2011). Patient Position on Cardiovascular and Pulmonary Function. Diunduh pada http://eknygos. lsmuni.lt/springer/414/410-417.pdf pada tanggal 15 Desember 2014.

Izzakovic, (2008). Central Venous Pressure: Evaluation, Intervention, Monitoring, Clinical Implication. Bratisl Leg Listy, 109(4). 
Setiyawan: Comparison of Central Venous Pressure (CPV) Score among Patients on Mechanical Ventilator

Kathleen M.V. (2010). Progressive Mobility in The Critically Ill. Critical Care Nurse, $30(2)$.

Kozier \& Erb, (2009). Buku Ajar Praktik Keperawatan Klinis Edisi 5. (Textbook of Clinical Nursing Practice 5th Edition). Jakarta : EGC.

Kim, H.J., Sohng, K.Y. (2006). Effects of Backrest Position on Central Venous Pressure and Intracranial Pressure in Brain Surgery Patients. Taehan Kanho Hakhoe Chi, 36(2):353-60.

Kim, S.H., Park, S.Y., Cui J., Lee, J.H., Cho S.H., Chae, W.S., Jin, H.C., and Hwang, K.H. (2011). Peripheral Venous Pressure as an Alternative to Central Venous Pressure in Patients Undergoing Laparoscopic Colorectal Surgery. British Journal of Anaesthesia. doi:10.1093/bja/aeq399.

Lan, C.C., Chang, C.Y., Peng, C.K., Wu, C.P., Huang, K.L., Lee, S.C., \& Chang, H. (2010). Effect Of Body Positions on Hemodynamics and Gas Exchange in Anesthetized Pigs Shortly after Pneumonectomy. Shock, 34(5), pp. 482 Y 487.

Linda. D., Kathleen, M., Mary, E. (2010). Critical Care Nursing: Diagnosis and Management 8th ed. St Louis: Mosby.

Lorenzo, D.R.A., Morris, M.J., Williams, J.B., Haley, T.F., Straight, T.M., HolbrookEmmons, V.L., Medina, J.S. (2012). Does a Simple Bedside Sonographic Measurement of The Inferior Vena Cava Correlate to Central Venous Pressure?. Journal Emergency Medical. 42(4):429-36. doi: 10.1016/j. jemermed.2011.05.082.

Maas, J.J., Geerts, B.F., Jansen, J.R.C. (2011). Evaluation of Mean Systemic Filling Pressure From Pulse Contour Cardiac Output and Central Venous Pressure. Journal of Clinical Monitoring and Computing, 25:19320. DOI: $10.1007 / \mathrm{s} 10877-011-9294-0$.

Marik, P.E., Monet, X., Teboul, J.L. (2011). Hemodynamic Parameters to Guide Fluid Therapy. Annals of Critical Care, 17(3): 290-
5. doi: 10.1097/MCC.0b013e32834699cd.

Marik, P.E, Cavallazzi R. (2013). Does The Central Venous Pressure Predict Fluid Responsiveness? an Updated Meta-Analysis and a Plea for Some Common Sense. Crit Care Med. 41:1774-1781.

Mulyati, T., Fatimah, S., Susilaningsih, F.S. (2012). Pengaruh Positive End Expiratory Pressure Terhadap Nilai Central Venous Pressure. (The Effect of Positive End Expiratory Pressure on the Value of Central Venous Pressure). Majalah Kedokteran Terapi Intensif, 2(3).

Polit, D. F., \& Beck, C.T. (2014). Essentials of Nursing Research: Appraising Evidence for Nursing Practice. (8th Ed). Philadelphia: Lippincott Williams, \& Wilkins.

Scales, K., Fernandes, M. (2010). Central Venous Pressure Monitoring in Clinical Practice. Nursing Standard, 24(29).

Sen, S., Aydin, K., Discigil, G. (2007). Hypotension Induced by Lateral Decubitus or Supine Spinal Anaesthesia in Elderly with Low Ejection Fraction Undergone Hip Surgery. Journal Of Clinical Monitoring And Computing, 21:103-107.

Siepe, M., Ruegg, D.M., Giraud, M.N., Python, J., Carrel, T., Tevaearai, H.T., (2005). Effect of Acute Body Positional Changes on The Hemodynamics of Rats With and Without Myocardial Infarction. Physiology in Press.

Thomas, P.J., Paratz, J.D., Lipman, J., Stanton, W.R. (2007). Lateral Positioning of Ventilated Intensive Care Patients: a Study of Oxygenation, Respiratory Mechanics, Hemodynamics, and Adverse Events. The Journal of Acute and Critical Care. Volume 36, Issue 4, Pages 277-286 DOI: http:// dx.doi.org/10.1016/j.hrtlng.2006.10.008.

Wiwatworapan, W., Ratanajaratroj, N., Sookananchai, B. (2012). Correlation Between Inferior Vena Cava Diameter and Central Venous Pressure In Critically Ill Patients. J Med Assoc Thai. 95(3):320-4. 
Setiyawan: Comparison of Central Venous Pressure (CPV) Score among Patients on Mechanical Ventilator

Yemima. (2007). Pengaruh Mobilisasi Pada Klien Stroke yang Mengalami Gangguan Fungsi Motorik Dengan Kejadian Dekubitus di Rumah Sakit Mardi Rahayu Kudus. (The Effect of Mobilization on Stroke Clients with Motor Function Disorders with Decubitus Incidents at Mardi Rahayu Kudus Hospital). Tesis. Tidak dipublikasikan. Semarang: PSIK FK UNDIP.
Yoon, S. Z.; Jeon, Y. S.; Bahk, J. H.; Kim, J. S. (2006). Reference Point for Central Venous Pressure Measurement in Lateral Decubitus Position. European Journal of Anaesthesiology, 23. 